\title{
High Prevalence of Depression, Anxiety and Stress Symptoms Among Diabetes Mellitus Patients
}

\author{
Abdulbari Bener ${ }^{*}, 1,2$, Abdulla O.A.A. Al-Hamaq ${ }^{3}$ and Elnour E. Dafeeah ${ }^{4}$ \\ ${ }^{I}$ Department of Medical Statistics \& Epidemiology, Hamad Medical Corporation, Dept. of Public Health, Weill Cornell \\ Medical College Doha, Qatar \\ ${ }^{2}$ Department of Evidence for Population Health Unit, School of Epidemiology and Health Sciences, University of \\ Manchester, Manchester, UK \\ ${ }^{3}$ Qatar Diabetic Associations and Qatar Foundation, Doha, Qatar \\ ${ }^{4}$ Department of Psychiatry, Psychology Unit, Rumailah Hospital, Hamad Medical Corporation, Qatar
}

Abstract: Background: Few studies have documented the rates of psychiatric symptoms in patients with Diabetes Mellitus (DM) patients and compared them with healthy controls.

Aim: To determine whether there is a relationship between high depression, anxiety, and stress symptoms in Diabetes Mellitus (DM) patients in comparison to a group of controls.

Design: This was a matched case-control study.

Setting: Primary Health Care (PHC) Centres of the Supreme Council of Health, State of Qatar.

Subjects: 889 DM patients and 889 healthy subjects matched for age, gender and ethnicity, from September 2009 to August 2010 were included in this study.

Methods: Face to face interviews were conducted with DM patients and controls using a questionnaire which captured the socio-demographic characteristics of subjects and the short version of the Depression Anxiety Stress Scales (DASS)-21 questionnaire. Furthermore, we used the questionnaire based on the Hospital Anxiety and Depression Scale (HADS) to assess the validity of DASS- 21 .

Results: The study findings revealed that most of the studied diabetic cases (33.6\%) and healthy controls (30.9\%) were in the 40-49 years age group. Significantly larger proportion of DM subjects had severe depression scores (13.6\% vs 5.9\%; $\mathrm{p}<0.001)$; severe anxiety scores $(35.3 \%$ vs $16.3 \%$; $<<0.001)$; and severe stress scores $(23.4 \% v s 10 \%$; $<<0.001)$ compared to healthy controls. The major predictors for high depression scores among diabetic cases were systolic blood pressure (OR 3.91; $\mathrm{p}=0.001)$, duration of diabetes (OR 2.68; $\mathrm{p}=0.011)$ and obesity (OR 2.50; $\mathrm{p}=0.001)$. The major predictors for high anxiety scores among diabetic cases were systolic blood pressure (OR 2.8; $\mathrm{p}=0.001$ ), obesity (OR 2.27; $\mathrm{p}=0.001$ ), and smoking (OR 1.78; $\mathrm{p}=0.04$ ). The leading predictors for high stress scores were systolic blood pressure (OR 3.57; $\mathrm{P}=0.001$ ), diastolic blood pressure (OR 2.80; $\mathrm{P}=0.001$ ) and physical activity (OR 2.11, $\mathrm{P}=0.025)$. Diabetic women had higher depression $(63.3 \%$ vs $50.4 \%$ ), anxiety $(70.1 \%$ vs $61.6 \%)$ and stress $(73.3 \%$ vs $61.4 \%)$ scores than men. No significant association was observed between the diabetic complications and depression, anxiety or stress scores.

Conclusion: The present findings revealed that diabetic cases had significantly higher depression, anxiety and stress scores compared to healthy controls. In particular anxiety scores were higher more frequently among diabetic patients in comparison to depression and stress scores.

Keywords: Diabetes mellitus, depression, anxiety, stress, prevalence, Qatar.

\section{INTRODUCTION}

DM is a major global public health problem which is increasing dramatically in developing countries [1]. The prevalence of DM worldwide is estimated to be around 200

*Address correspondence to this author at the Department of Medical Statistics \& Epidemiology, Hamad Medical Corporation and Department of Public Health, Weill Cornell Medical College, PO Box 3050, Doha, State of Qatar; Tel: +974- 4439 3765/+974- 4439 3766; Fax: 974-439 3769;

E-mails: abener@hmc.org.qa, abb2007@qatar-med.cornell.edu million people, more than $5 \%$ of the adult population globally [2]. Several factors contribute in T2DM pathogenesis, including environmental and lifestyle factors [3-5], positive family history [6], ethnicity [7], and genetics $[3,4,8]$. Previous studies conducted in the State of Qatar on the prevalence of $\mathrm{DM}$ indicate that $\mathrm{DM}$ is becoming increasingly common because of the epidemic of obesity and sedentary lifestyles [3, 4].

Among the many additional complications which coincide with DM, depression, anxiety, tension and stress are most commonly under-detected [9]. This is despite the fact 
that a growing body of literature has reported that patients with diabetes are almost twice as likely to suffer from anxiety and depression as the general population $[10,11]$. Also, such symptoms were associated with poor glycemic control, diabetes complications, worsened prognosis and quality of life [12]. To date, the overwhelming majority of these studies have used small sample sizes and very few were using a control group [13]. The aim of the current study is to determine the prevalence of anxiety, depression and stress symptoms among a large representative sample of DM patients using the short-form of the Depression Anxiety Stress Scales (DASS-21) instrument as compared with the general population.

\section{SUBJECTS AND METHODS}

This matched case-control study using surveys was performed at the primary health care (PHC) centers of the State of Qatar from September 2009 to August 2010. It was based on 889 DM cases and 889 control subjects, matched for age, gender and ethnicity. PHC centers are frequented by all levels of the general population as a gateway to specialist care. The study was approved by the Hamad General Hospital, Hamad Medical Corporation. All human studies have been approved by the Research Ethics Committee and have been performed in accordance with the ethical standards laid down in the 1964 Declaration of Helsinki.

Of the 22 PHC centres available, we selected 12 PHC centres at random. Of these, 9 were located in urban and three in semi-urban areas of Qatar. Finally, subjects were selected systematically 1-in-2 using a systematic sampling procedure. Each participant was provided with brief information about the study and was assured of strict confidentiality. The study excluded patients who were below 25 years and above 65 years, patients with any cognitive or physical impairment and who refused to give consent to take part in the study.

\section{Selection of Type 2 Diabetic (DM) Subjects}

Subjects reporting a history of DM, or currently taking oral medications or insulin for diabetes were considered as having DM. DM was defined according to the WHO Expert Committee group (2003) [14], i.e. fasting venous blood glucose concentration $\geq 7.0 \mathrm{mmol} / 1$ and $/$ or $2 \mathrm{~h}$ post-OGTT venous blood glucose concentration $\geq 11.1 \mathrm{mmol} / \mathrm{l}$. In all subjects, fasting blood glucose was determined by glucose meter and an oral glucose tolerance test (OGTT) was conducted only if blood sugar was $<7 \mathrm{mmol} / 1$. For the OGTT, subjects were requested to drink, within the space of $5 \mathrm{~min}$, $75 \mathrm{~g}$ anhydrous glucose dissolved in $250 \mathrm{ml}$ water. Samples were processed within 30 minutes of collection and the above laboratory tests were measured. Pre-diabetes status was based on the presence of impaired fasting glucose (venous blood glucose concentration for 5.6-6.9 mmol/l) or impaired glucose tolerance ( $2 \mathrm{Hrs}$ post-OGTT venous blood glucose level of $7.811 .0 \mathrm{mmol} / \mathrm{l})$ [3, 4]. A total number of 1088 eligible of DM patients aged above 25 years of age were selected systematically 1 -in-2 using a systematic sampling procedure of the PHC centres and 889 cases agreed to participate in the study with a response rate of $81.7 \%$.
$43 \%$ of DM subjects had dietary modification or no medication for treatment, while the remaining $57 \%$ of DM subjects were taking oral medications and/or insulin. The period of treatment for patients was on average 12 years.

\section{Selection of Controls}

Control subjects aged above 25 years were identified from community as healthy and if their venous blood glucose values were $<6.1 \mathrm{mmol} / \mathrm{L}$ and if they had never taken any diabetic medication. This group involved a random sample of 1126 healthy subjects who visited the PHC Centers for any reason other than acute or chronic disease. Of the 1126 healthy subjects approached, 889 healthy subjects were eligible and responded to our questionnaire, with a response rate of $(78.9 \%)$. The healthy subjects were selected in a way matching to the age and the gender of cases to give a good representative sample of the studied population.

Face-to-face interviews conducted by physicians and qualified trained nurses with subjects were used to complete the questionnaire that comprised personal data/demographic details. Furthermore, we used the short form of the DASS21; which participants took an average of 8 minutes to complete. DASS-21 is a short version of the original 42-item DASS-42 self report inventory [15], and consists of 21 symptoms divided into 3 subscales (depression, anxiety, and stress) of 7 items taken from DASS-42. DASS-21 measures the 3 dimensions specified in the tripartite model [16], and is associated with very good reliability estimates [17-19]. A 4point severity scale ranging from 0 (does not apply to me), to 3 (applies to me most or all of the time) measures the extent to which each state was experienced over the past week. Depressive (0-9, 10-20, and $>20)$, anxiety $(0-7,8-14$, and $>14)$, and stress $(0-14,15-25$, and $>25)$ symptom scores were categorized into normal, mild-moderate and severe, based on data obtained from previous testing of the scale [20]. It is important to note that while these scores are not diagnostic, they indicate the possible presence of depression, anxiety and stress in the subjects.

\section{Data Collection Tool}

We used the questionnaire based on the Hospital Anxiety and Depression Scale (HADS). To assess the validity of DASS-21, a group of patients $(n=50)$ and controls $(n=50)$ completed the 14-item Hospital Anxiety and Depression Scale (HADS) screening scale. The HADS consists of seven items for anxiety (HADS-A) and seven for depression (HADS-D). The items are scored on a four-point scale from zero (not present) to three [0-3] (considerable) [12, 21]. The depression scale (7 items, score range 0-21) measures mostly anhedonia, a phenomenon considered to be the central characteristic of major depressive disorder [21]. The anxiety scale (7 items, score range 0-21) measures mostly symptoms of generalized anxiety disorder [12]. For both HADS scales higher scores represent higher symptom levels. The depression and anxiety scales are intended to detect depressive and anxiety disorders in general medical settings. In this study valid HADS subscale scores were defined as having answered at least five of seven items on both the 
HADS-A and the HADS-D. The depression items were based on anhedonia, which is considered to be one of the essential criteria of depression [22]. The HADS-A had optimal cut off $\geq 8$ (sensitivity 0.87 , specificity 0.78 ), and the HADS-D had by optimal cut off $\geq 8$ (sensitivity 0.82 and specificity 0.86 ). The HADS scales generally used cut-off score of (cut off score $\geq 8$ ) and above was used to identify respondents with the possible presence of anxiety or depression [12, 21-24], but who scored below the cut-off score of 8 on either the anxiety or the depression subscale of the HADS were not considered as a case. In the Arabian performed study, the internal consistency of the HADS showed a Cronbach's coefficient alpha of 0.86. Excellent correlation concordance was observed between DASS-21 and HADS in assessing depression among DM patients and healthy subjects $(\rho=0.732 ; p<0.0001)$, anxiety among DM and healthy subjects $(\rho=0.715 ; p<0.0001)$ and stress among DM patients and healthy subjects $(\rho=0.786 ; p<0.0001)$. Content validity, face validity and reliability of the questionnaire were tested using $50 \mathrm{DM}$ patients and 50 controls. These tests demonstrated a high level of validity and high degree of repeatability (kappa $=0.86$ ).

\section{Statistical Analysis}

Student-t test was used to ascertain the significance of differences between mean values of two continuous variables and confirmed by non-parametric Mann-Whitney test. Chi-square and Fisher's exact test were performed to test for differences in proportions of categorical variables between two or more groups. Odds ratio (OR) and their $95 \%$ confidence intervals (CI) was calculated by using MantelHaenszel test. The multivariate stepwise logistic regression analysis was performed to find out the best predictors for diagnosis. The Pearson's and Spearman rank correlation coefficient was used to evaluate the strength association between two variables. Internal consistency of the HADS-A and the HADS-D was tested using Cronbach's coefficient alpha. Pearson's correlation coefficient was used for estimation of the overlap between the subscales. Sensitivity and specificity were calculated for different cut-off values for the HADS-A, the HADS-D. The level $\mathrm{p}<0.05$ was considered as the cut-off value for significance.

\section{RESULTS}

Table 1 shows the socio-demographic characteristics of the studied diabetic cases and healthy controls. Most of the studied diabetic cases (33.6\%) and healthy controls (30.9\%) were in the (40-49) years age group.

Table 2 reveals the depression, anxiety and stress scores in DM cases and healthy controls. While these scores are not diagnostic, they indicate the possible presence of depression, anxiety and stress in the subjects. Compared with the healthy controls, the depression scores were significantly higher and more frequent in diabetic cases; this was the case for both mild $(38.9 \%$ vs $26.5 \% ; \mathrm{p}<0.001)$ and severe depression $(13.6 \%$ vs $5.9 \% ; \quad \mathrm{P}<0.001)$ respectively. The scores for mild $(37.7 \%$ vs $26.8 \% ; \mathrm{P}<0.001)$ and severe anxiety $(35.3 \%$ vs $16.3 \% ; \mathrm{P}<0.001)$ were higher and more frequent in diabetic cases compared to healthy controls. Similarly, higher stress scores were significantly more frequent in DM cases where mild stress was present in $(46.6 \%$ vs $21.7 \%$; $\mathrm{P}<0.001)$ and severe stress symptoms were present in $(23.4 \%$ vs $10.0 \% ; \mathrm{P}<0.001)$.

Table 3 gives the results of stepwise logistic regression analysis as predictors of high depression, anxiety and stress scores among DM subjects. The most significant predictors for high depression scores were systolic $\mathrm{BP}(\mathrm{OR}=3.91$; $\mathrm{CI}$ 1.73-6.10 and $\mathrm{p}=0.001)$, duration of diabetes $(\mathrm{OR}=2.68$; $\mathrm{CI}$ $1.65-4.84$ and $\mathrm{p}=0.011)$, and obesity $(\mathrm{OR}=2.50$; CI 1.33-4.70 and $\mathrm{p}=0.001)$. Systolic $\mathrm{BP}(\mathrm{OR}=2.80$; CI $1.30-5.72$ and $\mathrm{p}=0.001)$, Obesity $(\mathrm{OR}=2.27$; CI $1.42-3.65$ and $\mathrm{p}=0.011)$ and smoking $(\mathrm{OR}=1.78$; CI 1.17-2.73 and $\mathrm{p}=0.04)$ were the most significant contributors for high anxiety scores among DM subjects. For high stress scores $(\mathrm{OR}=3.57$; CI 2.06-6.22 and $\mathrm{p}=0.001)$ systolic $\mathrm{BP}(\mathrm{OR}=3.57$; $\mathrm{CI} 2.06-6.22$ and $\mathrm{p}=0.001)$, diastolic BP (OR=2.80; CI 1.69-4.66 and $\mathrm{p}=0.001)$, and Physical inactivity $(\mathrm{OR}=2.11$; CI $1.13-3.94$ and $\mathrm{p}=0.025)$ were the major contributors.

Fig. (1) shows the distribution of high depression, anxiety and stress scores in DM subjects. High depression scores were more frequent among females (63.3\%) compared to males $(50.4 \%)$ with a ratio of $1: 1.2$. Also, anxiety $(70.1 \%$ vs $61.6 \% ; \mathrm{P}=0.009)$ and stress scores $(73.3$ vs 61.4; $\mathrm{P}<0.001)$ were higher and more frequent in women compared to men.

Fig. (2) presents the distribution of diabetic complications in patients with co-morbid depression, anxiety or stress symptoms. There was no significant association between the diabetic complications and psychiatric symptoms.

\section{DISCUSSION}

The present study addresses the question of possible relationship between depression, anxiety and stress in DM patients. The study findings suggest that depression, anxiety and stress symptoms are highly prevalent in DM patients. Despite the increasing confirmative evidence of this finding, psychiatry disorders such as depression, anxiety and stress often remain unrecognized and untreated in DM patients [10, $19,25,26]$. For instance, one study indicated that primary care physicians fail to detect depression in about $35-70 \%$ of cases [27]. Another study noted that only one-third of diabetes patients are treated with anti-depressant therapy by their diabetologist [28].

A growing number of studies in the international literature support the findings of this study that DM patients have an increased psychiatric morbidity $[8,10,19,25,26]$. Anderson et al. [10] documented in their study that approximately $30-40 \%$ of diabetic patients reported elevated depressive symptoms and $10-15 \%$ of diabetic patients suffer from a depressive disorder, according to clinical criteria. A similar pattern was observed in the present study that more than half of the DM patients were sufferers of depression symptoms $(52.5 \%)$, while $(13.6 \%)$ had severe depression 
Table 1. Socio-Demographics Characteristics of the Studied DM Cases and Healthy Controls $(\mathbf{N}=1778)$

\begin{tabular}{|c|c|c|c|c|}
\hline Variables & $\begin{array}{c}\text { Total } \\
\mathbf{n}=1778 \\
\text { n }(\%)\end{array}$ & $\begin{array}{c}\text { DM Patients } \\
\text { n= 889 } \\
\text { n (\%) }\end{array}$ & $\begin{array}{c}\text { Healthy Subjects } \\
\text { n= 889 } \\
\text { n (\%) }\end{array}$ & p-Value \\
\hline \multicolumn{5}{|l|}{ Age Group in years } \\
\hline$<30$ & $273(15.4)$ & $133(15.0)$ & $140(15.7)$ & \multirow{5}{*}{0.349} \\
\hline $30-39$ & $434(24.4)$ & $201(22.6)$ & $233(26.2)$ & \\
\hline $40-49$ & $574(32.2)$ & $299(33.6)$ & $275(30.9)$ & \\
\hline $50-59$ & $286(16.1)$ & $151(17.0)$ & $135(15.3)$ & \\
\hline$>60$ & $211(11.9)$ & $105(11.8)$ & $106(11.9)$ & \\
\hline \multicolumn{5}{|l|}{ Sex } \\
\hline Male & $938(52.8)$ & $458(51.5)$ & $480(53.9)$ & \multirow{2}{*}{0.318} \\
\hline Female & $840(47.2)$ & $431(48.5)$ & $409(46.1)$ & \\
\hline \multicolumn{5}{|l|}{ Nationality } \\
\hline Qatari & $859(48.3)$ & $422(47.5)$ & $437(49.2)$ & \multirow{2}{*}{0.253} \\
\hline Non-Qatari & $919(51.7)$ & $467(52.5)$ & $452(50.8)$ & \\
\hline \multicolumn{5}{|l|}{ Marital status } \\
\hline Single & $152(8.5)$ & $69(7.8)$ & $83(9.3)$ & \multirow{3}{*}{0.001} \\
\hline Married & $1481(83.3)$ & $778(87.5)$ & $703(82.5)$ & \\
\hline Widow/Divorce & $145(8.2)$ & $42(4.7)$ & 103(11.6) & \\
\hline \multicolumn{5}{|l|}{ Educational level } \\
\hline Illiterate & $324(18.2)$ & $131(14.7)$ & $193(22.1)$ & \multirow{5}{*}{$<0.001$} \\
\hline Primary & $321(18.1)$ & $144(16.2)$ & 177(19.9) & \\
\hline Intermediate & $351(19.7)$ & $187(21.0)$ & $164(18.4)$ & \\
\hline Secondary & $435(24.5)$ & $238(26.8)$ & $197(22.2)$ & \\
\hline University & $347(19.5)$ & $189(21.3)$ & $158(17.8)$ & \\
\hline \multicolumn{5}{|l|}{ Occupation } \\
\hline Not working/housewife & $483(27.2)$ & $215(24.2)$ & $268(30.1)$ & \multirow{5}{*}{0.564} \\
\hline Sedentary/professional & $527(29.6)$ & $271(30.5)$ & $256(28.8)$ & \\
\hline Clark/manual & $364(20.5)$ & $160(18.0)$ & 204(22.9) & \\
\hline Businessman & 194(10.9) & $92(10.3)$ & $102(11.5)$ & \\
\hline Army/Police/Security & $137(7.7)$ & $90(10.1)$ & $47(5.3)$ & \\
\hline \multicolumn{5}{|l|}{ Household Monthly Income* (QRs) } \\
\hline$<5000$ & $133(7.5)$ & $61(6.9)$ & $72(8.1)$ & \multirow{4}{*}{0.019} \\
\hline $5000-9999$ & $593(33.4)$ & $290(32.6)$ & $303(34.1)$ & \\
\hline $10,000-15,000$ & $604(34.0)$ & $286(32.2)$ & $318(35.8)$ & \\
\hline$>15,000$ & $448(25.1)$ & $252(28.3)$ & $196(22)$ & \\
\hline No. of bedrooms $($ Mean \pm SD) & $5.4 \pm 1.9$ & $5.7 \pm 1.7$ & $5.5 \pm 1.8$ & 0.565 \\
\hline No. people in house $($ Mean \pm SD) & $6.6 \pm 2.4$ & $6.8 \pm 2.2$ & $6.4 \pm 2.4$ & 0.675 \\
\hline \multicolumn{5}{|l|}{ Consanguinity } \\
\hline Yes & $690(38.8)$ & $325(36.6)$ & $365(41.1)$ & \multirow{2}{*}{0.029} \\
\hline No & $1088(61.2)$ & $564(63.4)$ & $524(58.9)$ & \\
\hline
\end{tabular}

*\$1 US Dollars $=3.65$ Qatari Riyals.

symptoms. The prevalence of severe depression symptoms in DM cases $(13.6 \%)$ was two fold higher than from the healthy controls (5.9\%). A study by Hermans et al. [26] indicated a great amount of diabetes related psychological distress in one-third of the sample with a significant association between depression status and diabetes, whereas in our 
Table 2. Prevalence of Depression, Anxiety and Stress Symptoms in DM Patients and Healthy Subjects

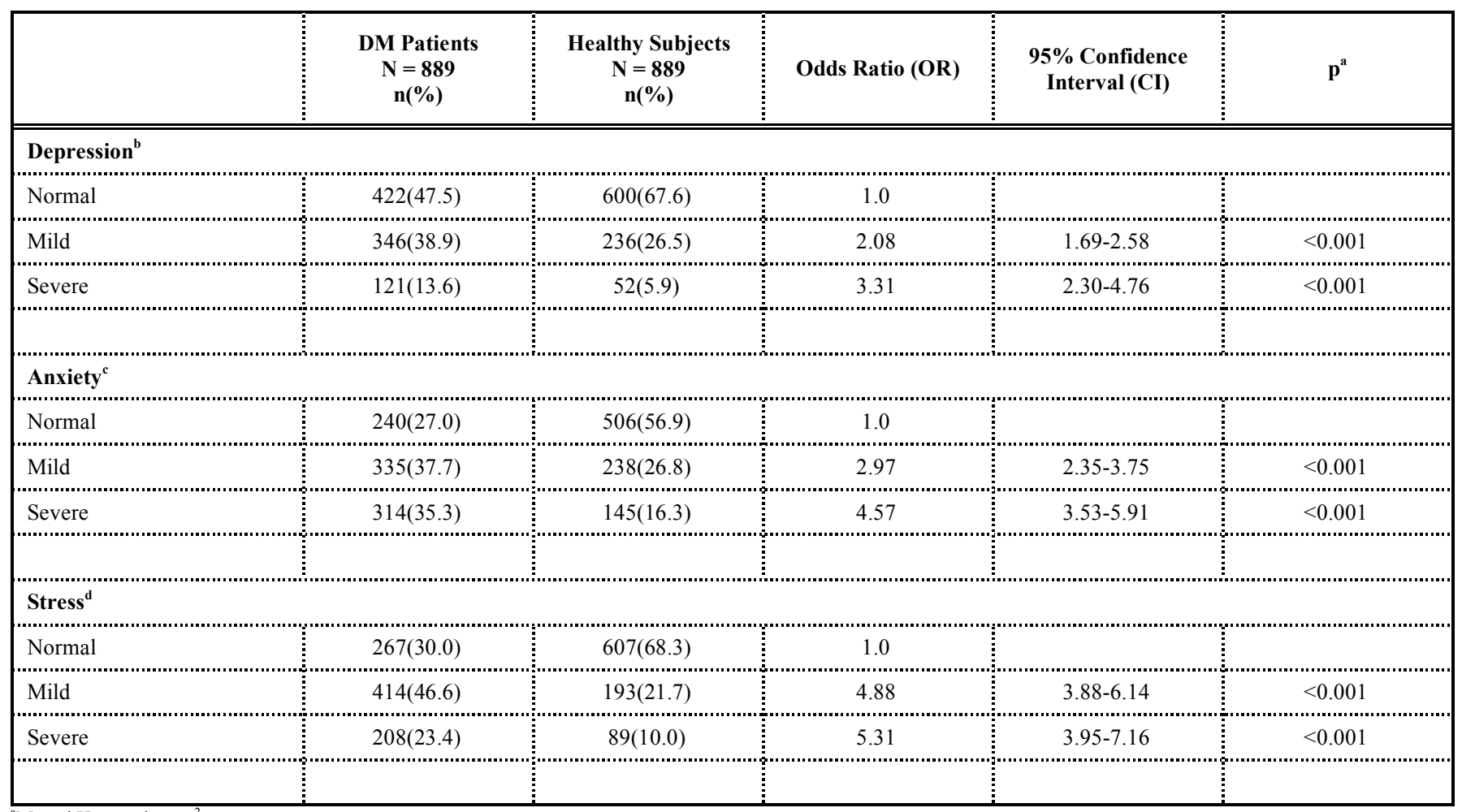

${ }^{\mathrm{a}}$ Mantel Haenszel test $x^{2}$ test.

${ }^{b}$ Depression was scored as per: normal (0-9), mild (10-20), and severe $(\geq 21)$.

${ }^{c}$ Anxiety scored as per: normal (0-7), mild (8-14), and severe $(\geq 15)$.

${ }^{\mathrm{d}}$ Stress scored as per: normal $(0-14)$, mild $(15-25)$, and severe $(\geq 26)$

study, depression symptoms were reported in half of the diabetic patients. Another study indicated that the prevalence of depression in diabetic patients was reported to vary between $8.5 \%$ and $27 \%$ [29] which is consistent with our prevalence rate of severe depression symptoms (13.6\%). A possible explanation for the differences in prevalence could be attributed to the different measurement scales used to determine the presence of depression.

Although our prevalence rate was slightly lower than the findings of two studies $(25 \%$ and $17.6 \%)$ [30], the prevalence of depression symptoms in our sample is very close to that of other studies of depression and diabetes [10, 31]. These study findings confirm that there is an association between depression symptoms and DM. While our findings, do not determine the direction of whether diabetes causes the onset of depression or vice versa, other studies have noted a direction. For example, a recent meta-analysis study concluded that depression increases the risk for DM by $37 \%$ [32]. Two years later, in the meta-analysis review, the risk for incident diabetes was $60 \%$ higher in depressed patients compared to non-depressed controls [33]. Two possible pathways have been proposed for this causation. The first pathway is via behavioral mechanisms, whereby emotional stress results in people adopting unhealthy lifestyle habits, which in turn lead to DM. The second pathway is physiological mechanisms, emotional stress causes biochemical changes in the body to occur which results in increased abdominal obesity and in turn DM [34].
In the present study, depression symptoms were significantly associated with the sex of the subjects studied with a male to female ratio of $1: 1.2$. This finding is in line with the other studies who reported depression to be significantly higher in diabetic women than in diabetic men $[35,36]$. A cross sectional study in Nigeria reported a male to female ratio of 1:3 [37]. It also concurs with another study [10] that reported depression to be significantly higher in diabetic women $(28 \%)$ than in diabetic men $(18 \%)$. These findings are similar to the general trend of gender distribution in the general population [35, 36, 38]. This could be attributable to gender-specific issues like pregnancy, menstrual cycle changes, post partum and additional stresses such as responsibilities at work and at home, single parenthood, caring for children and aging parents which could all lead to depression $[39,40]$.

In the study sample of diabetic patients, blood pressure, duration of diabetes, obesity and physical inactivity were significant risk factors for depression. The study did not find any association between depression and age groups of the diabetic patients, a finding which contrasts with that of another study who reported majority of the patients diagnosed with depression to be of younger age group [41]. A possible explanation for this discrepancy could be the different methodology used to document depressed patients and the fact that most of our cases and controls were in the 40-49 years age group.

It is found that anxiety is closely related to depression in diabetic patients. This relation is similar to previous reports 
Table 3. Results of Stepwise Logistic Regression Analysis as Predictors of Depression, Anxiety and Stress Symptoms Among DM Patients

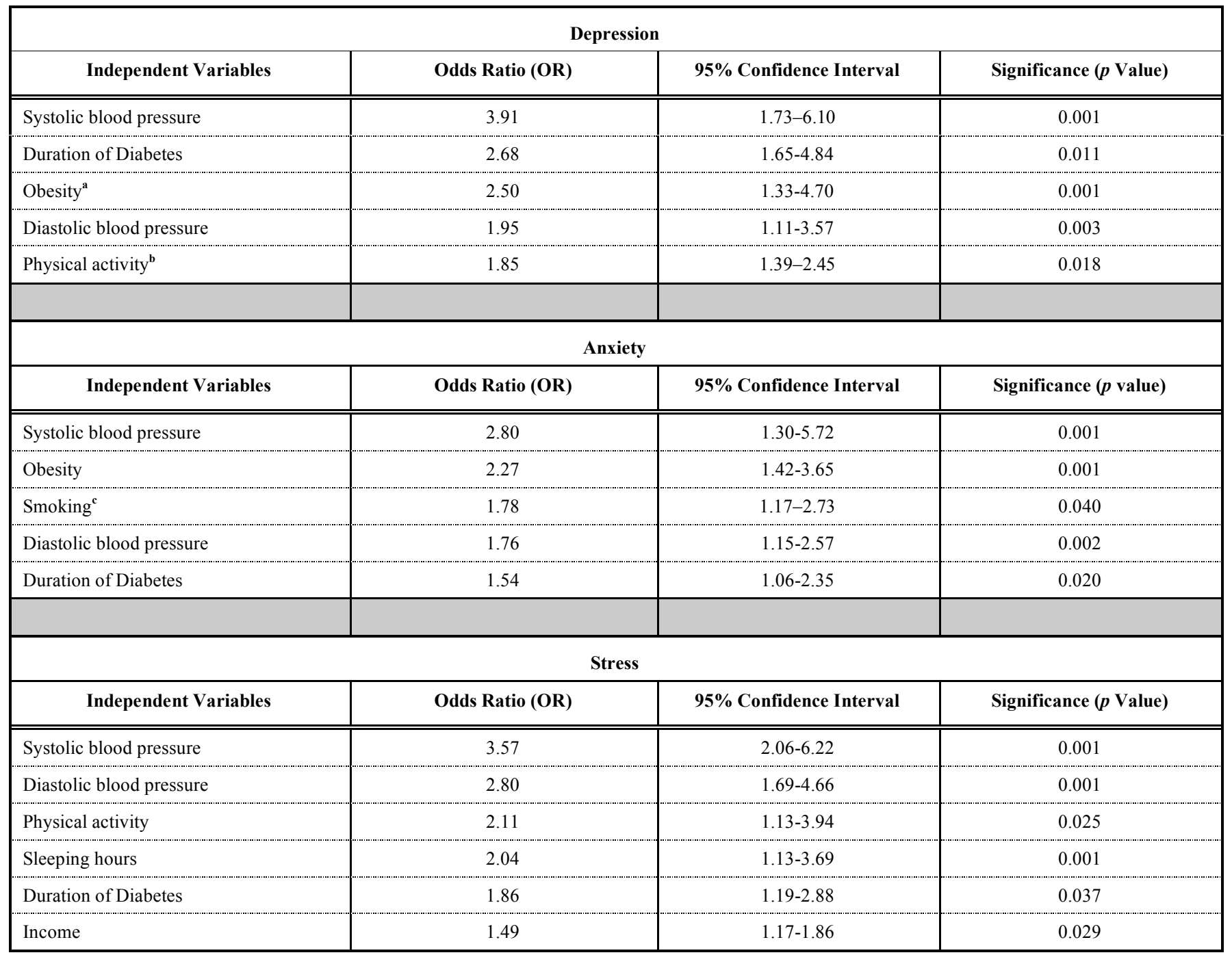

Adjusted for age and gender.

Note:

Obesity, physical activity and smoking considered as "Yes" or "No".

${ }^{a}$ Obesity (Yes) is: $>30$ BMI group $\left(\mathrm{kg} / \mathrm{m}^{2}\right)$.

${ }^{\mathrm{b}}$ Physical activity (Yes) is: walking $>30$ minutes/day.

'Smoking (Yes) is: "Previous and currently smoker".

showing that prevalence of anxiety and depression was common in diabetic patients [20]. But in the present study, anxiety was severe in diabetics $(35.3 \%)$ which are two fold higher than in non-diabetics (16.3\%). Also, the prevalence of anxiety $(35.3 \%)$ was nearly three times more than the depression rate (13.6\%). Compared with depressive symptoms, anxiety symptoms seem to be more specifically linked to diabetes in the current study. It is however, higher than the $25.2 \%$ prevalence of anxiety among diabetics reported in a study to assess the psychiatry morbidity among diabetics [26], but lower than the rate found in a study of (40\%) [42]. Also, Engum et al. [43] has tested anxiety as a risk factor for the development of diabetes in a large Norwegian population and found that the risk of DM was higher with high levels of anxiety. It was found that systolic blood pressure, obesity and smoking were significant predictors for anxiety in the diabetic study sample.

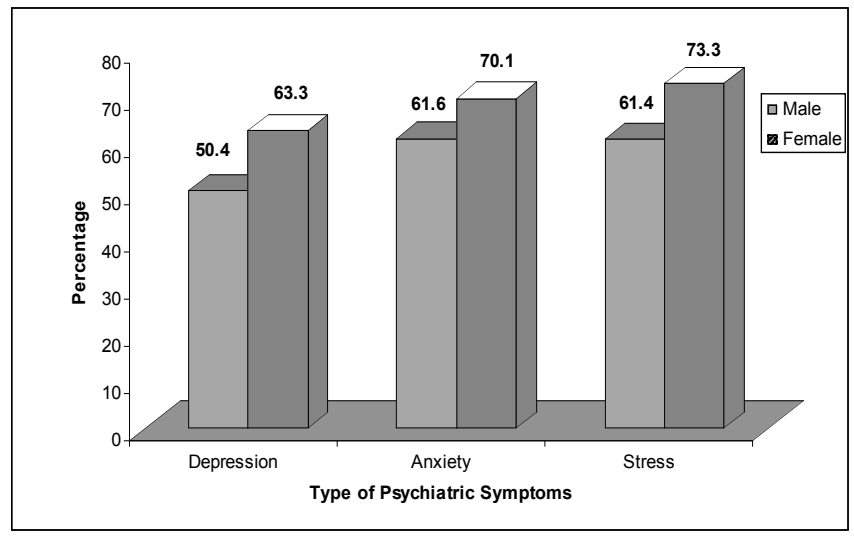

Note: Depression $P<0.001$, stress $P<0.001$ and Anxiety $P=0.009$.

Fig. (1). Distribution of Psychiatric Symptoms in DM patients by Gender. 


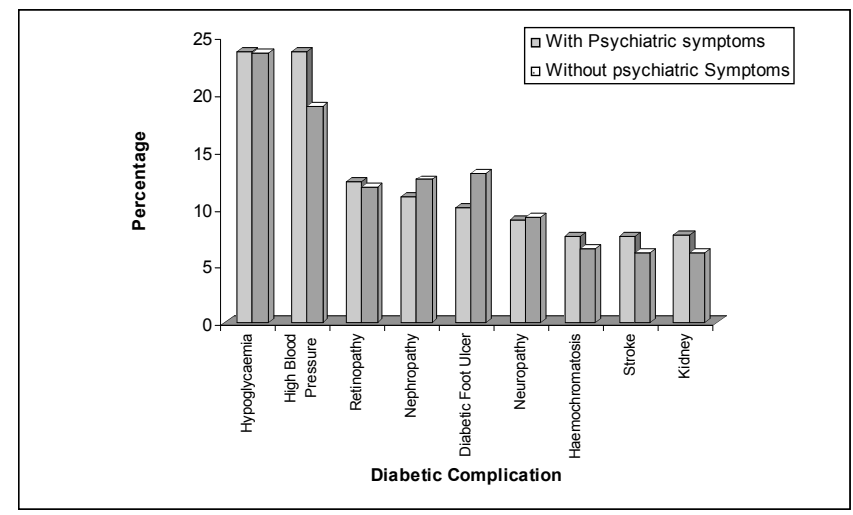

Fig. (2). Distribution of diabetic complications in diabetic patients with or without psychiatric symptoms.

Similar to depression and anxiety disorders, stress also has been positively linked to DM. Work stress has been reported to be associated with four fold higher risk of DM in Japanese men [44]. The prevalence of severe stress symptoms in the study sample of diabetics was $23.4 \%$ which is two fold higher than healthy controls $(10 \%)$. Moreover, a considerable number of depressed patients suffer from high levels of diabetes-specific emotional stress [45]. For stress symptoms, blood pressure, less physical activity and less sleeping hours were the significant predictors in DM patients.

In summary, there is evidence of high co-morbidity of diabetes and depression, anxiety and stress symptoms In Qatar. This is similar to a study done in this region, Bahrain [46], that examined the association of depression, anxiety and stress with DM; it found a positive contribution of T2DM to increased depression, anxiety and stress disorders among diabetic patients. The reasons for high morbidity of psychiatric disorders and DM are not fully understood. The authors of the current study concluded that the occurrence of psychiatric symptoms appeared to be independent of diabetes complications because both the depressed and reference groups had a similar rate of complications like hypoglycemia, neuropathy, retinopathy and nephropathy except for high blood pressure. This is in line with another study that psychiatry morbidity was not associated with the presence of complications of diabetes [47].

A potential limitation to the current study was use of the DASS-21 instrument which only determines the presence of depression, anxiety and stress symptoms, rather than conducting a diagnostic interview which would have conclusively determined the prevalence of depression, anxiety and stress in the population. Moreover, the cross-sectional design of this study inevitably limits the capacity of the data to project a direction of causation in relation to DM and psychiatry disorders. Nonetheless, this study has some strengths which make it a worthy contribution to the growing body of literature on DM and psychiatric co-morbidity. It is one of the few matched case control studies, with a large population based sample size, to be conducted on the subject [13].

\section{CONCLUSION}

The present study revealed that there is evidence of high co-morbidity of DM and depression, anxiety and stress symptoms in Qatar. Anxiety symptoms were more prevalent than depression and stress symptoms in DM patients. Depression and anxiety symptoms were severe in DM cases, which is two fold higher than in healthy controls. Depression, anxiety and stress symptoms were significantly associated with sex of the diabetic patients, with a higher prevalence in women. Diabetes appears to increase the risk of developing psychiatry disorders; therefore early detection and treatment intervention are required for diabetic patients.

\section{ACKNOWLEDGMENTS}

This study was generously supported and funded by the Qatar Diabetic Association and Qatar National Research Fund- QNRF NPRP 30-6-7-38. The authors would like to thank the Hamad Medical Corporation for their support and ethical approval (HMC \# RP 7100/07).

\section{REFERENCES}

[1] Shaw JE, Sicree RA, Zimmet PZ. Global estimates of the prevalence of diabetes for 2010and 2030. Diabetes Res Clin Pract 2010; 87: 4-14.

[2] Wild S, Roglic G, Green A, Sicree R, King H. Global prevalence of diabetes: estimates for the year 2000 and projections for 2030 . Diabetes Care 2004; 27 : 1047-53.

[3] Bener A, Zirie M, Janahi IM, Al Hamaq AOAA, Musallam M, Wareham NJ. Prevalence of diagnosed and undiagnosed diabetes mellitus and its risk factors in a population - based study of Qatar. Diabetes Res Clin Pract 2009; 84: 99-106.

[4] Bener A, Zirie M, Musallam M, Khader YS, Al-Hamaq AOAA. Prevalence of metabolic syndrome according to ATP III and IDF criteria: a population based study. Metab Syndr Relat Disord 2009; 7: 221-30.

[5] Kriska AM, Saremi A, Hanson RL, et al. Physical activity, obesity, and the incidence of type 2 diabetes in a high-risk population. Am J Epidemiol 2003; 158: 669-75.

[6] Erasmus RT, Blanco Blanco E, Okesina AB, Mesa AJ, Gqweta Z Matsha T. Importance of family history in type 2 black South African diabetic patients. Postgrad Med J 2001; 77: 323-5.

[7] Abate N, Chandalia M. The impact of ethnicity on type 2 diabetes. J Diabetes Complications 2003; 17: 39-58.

[8] Sesti G, Federici M, Lauro D, Sbraccia P, Lauro R. Molecular mechanism of insulin resistance in type 2 diabetes mellitus: role of the insulin receptor variant forms. Diabetes Metab Res Rev 2001; 17: 363-73.

[9] Pouwer F, Beekman AT, Lubach C, Snoek FJ. Nurses' recognition and registration of depression, anxiety and diabetes-specific emotional problems in outpatients with diabetes mellitus. Patient Educ Couns 2006; 60: 235-40.

[10] Ghuloum S, Bener A, Burgut FT. Ethnic Differences in Satisfaction with Mental Health Services among Psychiatry Patients. Open Psychiatr J 2010; 4: 19-24.

[11] Peyrot M, Rubin RR. Levels and risks of depression and anxiety symptomatology among diabetic adults. Diabetes Care 1997; 20: 585-90.

[12] Lustman PJ, Anderson RJ, Freedland KE, de Groot M, Carney RM, Clouse RE. Depression and poor glycemic control: a meta-analytic review of the literature. Diabetes Care 2000; 23: 934-42.

[13] Nichols GA, Brown JB. Unadjusted and adjusted prevalence of diagnosed depression in Type 2 Diabetes. Diabetes Care 2003; 26:744-9.

[14] The Expert Committee on the Diagnosis and Classification of Diabetes Mellitus. Report of the Expert Committee on the Diagnosis and Classification of Diabetes Mellitus. Diabetes Care 2003; 26 : S5-S20.

[15] Levibond PF, Levibond SH. The structure of negative emotional states: comparison of the depression anxiety stress scales (DASS) with the beck depression and anxiety inventories. Behav Res Ther 1995; 33: 335-43.

[16] Brown TA, Chorpita BF, Korotitsch W, Barlow DH. Psychometric properties of the Depression Anxiety Stress Scales (DASS) in clinical samples. Behav Res Ther 1997; 35: 79-89. 
[17] Clara IP, Cox BJ, Enns MW. Confirmatory factor analysis of the depression-anxiety-stress scales in depressed and anxious patients. J Psychopathol Behav Assess 2001; 23: 61-7.

[18] Henry JD, Crawford JR. The short-form version of the Depression Anxiety Stress Scales (DASS-21): construct validity and normative data in a large non-clinical sample. Br J Clin Psychol 2005; 44: 227-39.

[19] De Groot M, Anderson R, Freedland KE, Clouse RE, Lustman PJ. Association of depression and diabetes complications: a metaanalysis. Psychosom Med 2001; 63: 619-30.

[20] Fisher L, Skaff MM, Mullan JT, Arean P, Glasgow R, Masharani U. A longitudinal study of affective and anxiety disorders, depressive affect and diabetic distress in adult with type $2 \mathrm{DM}$. Diabet Med 2008; 25:1096-101.

[21] King H, Aubert RE, Herman WH. Global burden of diabetes, 19952025 - Prevalence, numerical estimates, and projections. Diabetes Care 1998; 21:1414-31.

[22] Ghuloum S, Bener A, Burgut FT. Epidemiological survey of knowledge, attitude and health literacy mental illness in a national community sample: a global burden disease. J Prim Care Community Health 2010; 1:111-18.

[23] Aikens JE, Perkins DW, Lipton B, Piette JD. Longitudinal analysis of depressive symptoms and glycemic control in type 2 diabetes. Diabetes Care 2009; 32: 1177-81.

[24] Bener A, Guloum S. Gender differences on the knowledge attitude and beliefs towards mental health illness in a very rapid arab developing society. Int J Soc Psychiatry 2011; 57: 480-6.

[25] Mosaku K, Kolawole B, Mume C, Ikem R. Depression, anxiety and quality of life among diabetic patients: a comparative study. J Natl Med Assoc 2008; 100:73-8.

[26] Hermans N, Kulzer B, Krichbaum M, Kubiak T, Haak T. How to screen for depression and emotional problems in patients with diabetes: Comparison of screening characteristics of depression questionnaires, measurement of diabetes-specific emotional problems and standard clinical assessment. Diabet Med 2005; 22: 293-300.

[27] Valenstein M, Vijan S, Zeber JE, Boehm K, Buttar A. The costutility of screening for depression in primary care. Ann Intern Med 2001; 134: 345-60.

[28] Lustman PJ, Harper GW. Non-psychiatric physicians' identification and treatment of depression in patients with diabetes. Compr Psychiatry 1987; 28:22-7.

[29] Schram MT, Baan CA, Pouwer F. Depression and quality of life in patients with diabetes: a systematic review from the European depression in diabetes (EDID) research consortium. Curr Diabetes Rev 2009; 5:112-9.

[30] Davies M, Dempsler M, Malone A. Do people with diabetes who need to talk want to talk? Diabet Med 2006; 23: 917-9.

[31] Kruse J, Schmitz N, Thefeld N. The association between diabetes and mental disorders in a community sample. Diabetes Care 2001; $24: 1069-78$.
[32] Knol M, Twisk J, Beekman A, Heine R, Snoek F, Pouwer F. Depression as a risk factor for the onset of type $2 \mathrm{DM}$. Diabetologia 2006; 49: 837-45.

[33] Mezuk B, Eaton WW, Albrecht S, Golden SH. Depression and type 2 Diabetes over the life span. Diabetes Care 2008; 31: 2383-90.

[34] Pouwer F, Kupper N, Adriaanse MC. Does emotional stress cause type 2 diabetes mellitus? A review from the European Depression in Diabetes (EDID) Research Consortium. Discov Med 2010; 9:112-8.

[35] Murakumi J. Gender and depression: explaining the different rates of depression between men and women. Perspect Psychol 2002; Spring: 27-34.

[36] Piccinelli M, Wilkinsen G. Gender differences in depression: critical review. Br J Psychiatry 2000; 177: 486-92.

[37] Agbir TM, Audu MD, Adebowale TO, Goar SG. Depression among medical outpatients with diabetes: A cross sectional study at Jos University Teaching Hospital, Jos, Nigeria. Ann Afr Med 2010; 9: 5-10.

[38] Gafvels C, Wandell PE. Coping strategies in men and women with type 2 diabetes in Swedish primary care. Diabetes Res Clin Pract 2006; 71: 280-9.

[39] Legato MJ, Gelzer A, Goland R, et al. The writing group for the partnership for gender-specific medicine. gender-specific care of the patient with diabetes: review and recommendations. Gend Med 2006; 3:131-58.

[40] Blazer DG, Moody-Ayers S, Craft-Morgan J, Burchett B. Depression in diabetes and obesity: racial/ethnic/gender issues in older adults. J Psychosom Res 2002; 534: 913-6.

[41] Gregory AN, Jonathan BB. Unadjusted and adjusted prevalence of diagnosed depression in type 2 DM. Diabetes Care 2003; 26:744-9.

[42] Grigsby AB, Anderson RJ, Freedland KE, Clouse RE, Lustman PJ. Prevalence of anxiety in adults with diabetes: a systematic review. J Psychosom Res 2002; 53: 1053-60.

[43] Engum A. The role of depression and anxiety in onset of diabetes in a large population based study. J Psychosom Res 2007; 62:31-8.

[44] Kawakami N, Araki S, Takatsuka N, Shimizu M, Ishibashi H Overtime, psychosocial work conditions and occurrence of noninsulin dependent DM in Japanese men. J Epidemiol Commun Health 1999; 53: 359-63.

[45] Kokoszka A, Pouwer f, Jodko A, et al. Serious diabetes-specific emotional problems in patients with type $2 \mathrm{DM}$ who have different levels of co-morbid depression: a Polish study from the European Depression in Diabetes (EDID) Research Consortium. Eur Psychiatry 2009; 24: 425-30.

[46] Almawi W, Tamim H, Al-Sayed N, et al. Association of co-morbid depression, anxiety and stress disorders with type $2 \mathrm{DM}$ in Bahrain, a country with a very high prevalence of type 2 DM. J Endocrinol Invest 2008; 31: 1020-4.

[47] Wilkinson G, Borsey DQ, Leslie P, Newton RW, Lind C, Ballinger CB. Psychiatry morbidity and social problems in patients with insulin dependent diabetes mellitus. Br J Psychiatry 1988; 153: 3843

Received: August 24, 2011

(C) Bener et al.; Licensee Bentham Open.

This is an open access article licensed under the terms of the Creative Commons Attribution Non-Commercial License (http://creativecommons.org/licenses/by-nc/ 3.0/) which permits unrestricted, non-commercial use, distribution and reproduction in any medium, provided the work is properly cited. 